\title{
The relationships among Pilates instructors' emotional labor, job burnout, and occupational identity
}

\author{
Su Yeon Roh* \\ Department of Exercise Rehabilitation and Welfare, College of Health Science, Gachon University, Incheon, Korea
}

This study aimed to investigate the relationships among the emotional labor, job burnout, and occupational identity of Pilates instructors. Instructors conducting Pilates classes in the Seoul, Gyeonggi, and Incheon areas were selected as the study population to achieve the aforementioned goal, and a total of 195 datasets were utilized for the actual analysis, using the convenience sampling method. The analysis methods that were employed for the study include frequency analysis, confirmatory factor analysis, reliability verification, correlation analysis, and structural equation model analysis, and the following conclusions were obtained in the process: (a) the internal behaviors of the Pilates instructors' emotional labor had a negative effect on the instructors' job burnout; (b) the surface behaviors of the Pilates instructors' emotional labor had a positive effect on the instructors' job burnout; (c) the job burnout of the Pilates instructors had a negative effect on their occupational identity; (d) the internal behaviors of the Pilates instructors' emotional labor had a positive effect on the instructors' occupational identity; and (e) the surface behaviors of the Pilates instructors' emotional labor had a negative effect on the instructors' occupational identity.

Keywords: Pilates, Instructors, Emotional labor, Job burnout, Occupational identity

\section{INTRODUCTION}

There are several buzzwords reflecting the current trend of the health-obsessed modern society, and among these are "well-being" and "wellness." It cannot be denied that the significance of these terms largely relies on physical activity for sustaining health. Leisure activities based on physical exercises are increasing rapidly as well, prompting the prediction that the increasing trend will continue in the future (Bullo et al., 2015).

Pilates is a representative physical activity in this context that can accommodate the social demand for pursuing a healthy lifestyle. It is gaining increasing importance because it belongs to a "field of physical activity" that enables efficient exercise in a narrow space and with a busy daily life, thus defying the constraints of urbanization. In addition, Pilates is attracting an increasing number of adherents because it gives them an opportunity to elevate the quality of their life in various aspects (Maguire, 2001; Roh, 2016). The efforts for the commercialization and specializa- tion of Pilates have been in full swing of late, in an effort to capitalize on the aforementioned trend, with various programs being offered to induce people's interest and to enable them to achieve their exercise goals. Above all, Pilates is living up to its customers' desire by providing "personalized exercise" that matches the physical characteristics and exercise goals of its individual users (Roh, 2018).

The majority of Pilates instructors are assistants who provide personalized programs on a personal level and who guide Pilates adherents to exercise effectively and safely so as to achieve their individual fitness and health goals. The demand for Pilates instructors is also increasing every day, along with the increasing demand for Pilates (Kim, 2011). Pilates instructors are sports professionals equipped with matching qualifications, including experience, knowledge, and expertise, because they are required to possess a license (Koo et al., 2010). Therefore, the instructors' personality and attitude, which are key to building relationships, must be regarded as core elements that would be immediately re-
${ }^{*}$ Corresponding author: Su Yeon Roh (iD https://orcid.org/0000-0001-5573-5870 Department of Exercise Rehabilitation and Welfare, College of Health Science, Gachon University, 191 Hambangmoe-ro, Yeonsu-gu, Incheon 21936, Korea E-mail: rsypilates@naver.com

Received: June 2, 2019 / Accepted: July 9, 2019
This is an Open Access article distributed under the terms of the Creative Commons Attribution Non-Commercial License (http://creativecommons.org/licenses/by-nc/4.0/) which permits unrestricted non-commercial use, distribution, and reproduction in any medium, provided the original work is properly cited. 
flected in their satisfactory services. In addition, from the viewpoint of instructors, the higher their job performance is, the higher the satisfaction of the Pilates adherents, thereby promoting the development of a more virtuous-circle structure that can determine the management performance.

Pilates instructors strive to maximize their capabilities and to provide customized services that take into account the personal characteristics of their clients. They provide services in an intangible form in this process, highlighting the significant roles of the instructors' emotions and emotional expressions in satisfying their clients. The instructors are required to provide instruction in a kind manner, to satisfy the clients. Therefore, they strive to induce positive feelings in their individual clients. As Pilates instructors are also human beings, however, there is a limit to the extent to which they can accommodate the individual characteristics of all their clients. In other words, the instructors conduct emotional labor so they would always wear a smile, and strive to manage their external expression despite being tired or troubled (Roh, 2016).

Accordingly, the workers in the education service sector are classified as emotional laborers as they are required to smile at all times (Lee et al., 2016). Emotional labor is a special type of labor that turns emotions, which are part of the nature of human beings, into things with exchangeable values, and then sells them as commodities. It is a type of labor that expresses emotions in a form recognized as suitable for an efficient work process rather than as they really are. In the workplace, people try to express emotions that are different from what they are really feeling. These efforts are quite stressful for Pilates instructors. They thus eventually manifest the symptoms of job burnout, such as helplessness (Lee et al., 2016). Job burnout is defined as physical and emotional exhaustion, including negative self-perception, a negative attitude towards work, and loss of interest in or empathy towards the customers (Maslach and Jackson, 1981). Job burnout adversely affects various psychological, physical, and behavioral aspects. It has also been found to be closely related to the job performance of individual employees (Grandey, 2000). To sum up, job burnout has a direct impact on occupational identity as they are both correlated with the workers' emotional attitudes ( $\mathrm{Yi}$ and Sim, 2010).

This study is significant, therefore, in that it will increase the occupational identity of Pilates instructors and help them provide effective educational services to their clients by helping them identify their emotional labor from an objective viewpoint, and prevent job burnout. The purpose of this study was to investigate the effects of Pilates instructors' emotional labor on their job burnout and occupational identity. The following hypotheses were laid out.

Hypothesis 1. The internal behaviors of the Pilates instructors' emotional labor have a negative effect on such instructors' job burnout. Hypothesis 2. The surface behaviors of the Pilates instructors' emotional labor have a positive effect on such instructors' job burnout. Hypothesis 3. Pilates instructors' job burnout has a negative impact on their occupational identity. Hypothesis 4. The internal behaviors of the Pilates instructors' emotional labor have a positive effect on such instructors' occupational identity. Hypothesis 5. The surface behaviors of the Pilates instructors' emotional labor have a negative impact on such instructors' occupational identity.

\section{MATERIALS AND METHODS}

\section{Subjects}

The study subjects were set as the population of Pilates instructors who were teaching Pilates as of 2019. The samples were extracted from the Pilates instructors in Seoul, Gyeonggi, and Incheon Metropolitan City using the convenience sampling method among the nonprobability sampling methods. Of the total of 230 survey questionnaire copies that were distributed, 210 were retrieved, but only 195 copies (excluding the 15 that were responded to unfaithfully) were used for the actual analysis. The general characteristics of the study subjects are shown in Table 1.

\section{Research tools}

A questionnaire survey was used in this research. The questionnaire consisted of 28 items, including those on the respondents' demographic characteristics, five items on emotional labor, ten on job burnout, and seven on occupational identity. In this study, emotional labor was measured using items that were modified and supplemented based on the study results obtained by various researchers (Austin et al., 2008; Brotheridge and Lee, 2002) as emotional labor, which was set as an independent variable in this study, tends to be divided into internal and surface behaviors (Hochschild, 1979).

For job burnout, which was set as a mediating variable, Malash Burnout Inventory (MBI), developed overseas, was used (Maslach and Jackson, 1981). MBI consists of 25 items, but the items on job burnout that were used in this study were revised and supplemented to reflect the situation in South Korea. To sum up, the questionnaire consisted of four items on emotional exhaustion, three on emotional exhaustion stemming from work overload, and 
Table 1. Study participants' characteristics

\begin{tabular}{lr}
\hline Characteristic & No. (\%) \\
\hline Sex & \\
Man & $46(23.6)$ \\
Woman & $149(76.4)$ \\
Age (yr) & \\
Under 30 & $62(31.8)$ \\
$30-40$ & $93(47.7)$ \\
Over 40 & $40(20.5)$ \\
Career (yr) & \\
Less than 1 & $39(20.0)$ \\
$1-3$ & $45(23.1)$ \\
$3-5$ & $68(34.9)$ \\
Over 5 & $43(22.0)$ \\
Education & \\
High school & $32(16.4)$ \\
University level & $46(23.6)$ \\
University graduate & $85(43.6)$ \\
Graduate school & $32(16.4)$ \\
Salary level (KRW) & \\
Under 1.5 million & $45(23.1)$ \\
1.5-3.0 million & $122(62.6)$ \\
Over 3.0 million & $28(14.3)$ \\
\hline
\end{tabular}

KRW, Korean won.

three on impersonalization, including apathy towards one's colleagues.

For occupational identity, which was set as a dependent variable in this study, it was measured using items from Occupation Identity Scale developed by Melgosa (1987) that were modified and supplemented to fit the present study, with three questions on self-esteem and four on intention to continue. The contents of the items suggest the pleasant and positive emotional state obtained by evaluating an individual's job or job experience. In other words, they were classified into internal satisfaction, which is expressed via satisfaction with the job itself, such as self-realization and sense of achievement; external satisfaction, which is obtained from job performance; and external satisfaction, which means satisfaction with one's obtained benefits. Each item was rated based on a 5-point Likert scale, with 1 meaning "strongly disagree"; 2 , "disagree"; 3 , "undecided”; 4, "agree”; and 5, "strongly agree."

\section{Validity and reliability of the questionnaire}

To test the validity of the questionnaire that was used in this study, exploratory factor analysis was used, while factor rotation was performed using a right-angle rotation method. Two factors were extracted from the factor analysis of the six questionnaire
Table 2. Exploratory factor analysis of emotional labor

\begin{tabular}{lcc}
\hline Item & Inner behavior & Surface behavior \\
\hline 5 & 0.864 & 0.320 \\
2 & 0.846 & -0.268 \\
6 & 0.821 & 0.229 \\
1 & 0.325 & 0.835 \\
4 & 0.293 & 0.779 \\
3 & 0.196 & 0.754 \\
Eigenvalue & 2.366 & 2.119 \\
Variance $(\%)$ & 39.433 & 35.316 \\
Accumulation $(\%)$ & 39.433 & 74.749 \\
Cronbach $\alpha$ & 0.811 & 0.804
\end{tabular}

$\mathrm{KMO}=0.759 ; \chi^{2}=2,843.452 ; \mathrm{Sig}=0.000$.

Table 3. Exploratory factor analysis of job burnout

\begin{tabular}{lccc}
\hline Item & $\begin{array}{c}\text { Achievement } \\
\text { lowering }\end{array}$ & $\begin{array}{c}\text { Emotional } \\
\text { exhaustion }\end{array}$ & Impersonalization \\
\hline 1 & 0.875 & 0.322 & 0.310 \\
9 & 0.866 & 0.134 & 0.109 \\
10 & 0.832 & 0.089 & 0.100 \\
7 & 0.813 & 0.085 & 0.069 \\
8 & 0.398 & 0.789 & 0.296 \\
6 & 0.334 & 0.774 & 0.261 \\
3 & 0.110 & 0.752 & 0.106 \\
2 & 0.316 & 0.310 & 0.732 \\
4 & 0.309 & 0.281 & 0.714 \\
5 & 0.209 & 0.133 & 0.703 \\
Eigenvalue & 3.389 & 2.118 & 1.830 \\
Variance (\%) & 38.890 & 21.181 & 18.300 \\
Accumulation $(\%)$ & 38.890 & 60.071 & 78.371 \\
Cronbach $\alpha$ & 0.810 & 0.834 & 0.746 \\
\hline
\end{tabular}

$\mathrm{KMO}=0.746 ; \chi^{2}=2,715.325 ; \mathrm{Sig}=0.000$.

items on emotional labor, while the factor load of the internal behaviors was measured as $0.821-0.864$ and that of the surface behaviors was measured as $0.754-0.835$. In addition, the Cronbach a of emotional labor showed a reliable value of $0.804-0.811$, as shown in Table 2.

Three factors were extracted as a result of the factor analysis of the ten questionnaire items on job burnout. Among them, the factor load of reduced sense of achievement was determined to be reasonable at $0.813-0.875$, that of emotional exhaustion was $0.752-0.789$, and that of impersonalization was $0.703-0.732$. In addition, the Cronbach $a$ of job burnout was determined to be reliable at $0.746-0.834$, as shown in Table 3.

Two factors were extracted as a result of the factor analysis of the seven items on occupational identity. It was found that the 
Table 4. Exploratory factor analysis of occupational identity

\begin{tabular}{lcc}
\hline Item & Self-esteem & Intention to continue \\
\hline 3 & 0.812 & 0.284 \\
1 & 0.808 & 0.272 \\
2 & 0.798 & 0.135 \\
6 & 0.163 & 0.721 \\
5 & 0.213 & 0.682 \\
7 & 0.206 & 0.631 \\
8 & 0.412 & 0.623 \\
Eigenvalue & 2.231 & 1.943 \\
Variance (\%) & 31.873 & 27.757 \\
Accumulation (\%) & 31.873 & 59.630 \\
Cronbach $\alpha$ & 0.875 & 0.841
\end{tabular}

$\mathrm{KMO}=0.846 ; \chi^{2}=2,012.315 ; \mathrm{Sig}=0.000$.

Table 5. Correlation analysis between the variables

\begin{tabular}{lcccc}
\hline Variable & 1 & 2 & 3 & 4 \\
\hline Inner behavior & 1 & & & \\
Surface behavior & $0.171^{*}$ & 1 & & \\
Job burnout & $-0.213^{* *}$ & $0.312^{* *}$ & 1 & \\
Occupational identity & $0.284^{* *}$ & $-0.165^{*}$ & $-0.462^{* * *}$ & 1 \\
\hline
\end{tabular}

${ }^{*} P<0.05$. ${ }^{* *} P<0.01$. ${ }^{* *} P<0.001$.

factor load of self-esteem was 0.798-0.812, and that of intention to continue was $0.623-0.721$. In addition, the Cronbach $\alpha$ of occupational identity was found to have a reliable level of $0.841-$ 0.875 , as can be seen in Table 4 .

\section{Data processing method}

A total of 323 valid samples out of the 355 distributed questionnaire copies were collected, excluding the 32 samples that were deemed to be unfaithful or to have had missing responses. Frequency analysis, confirmatory factor analysis, correlation analysis, and structural equation model analysis were then conducted on the valid samples using IBM SPSS Statistics ver. 23.0 (IBM Co., Armonk, NY, USA) and IBM SPSS AMOS ver. 20.0 (IBM Co.), for model analysis.

\section{RESULTS}

\section{Correlation between the Pilates instructors' emotional labor and job burnout/occupational identity}

Correlation analysis was conducted to determine the degree of discriminant validity among the factors that had been proven to have single dimensionality via confirmatory factor analysis. The results showed that the correlations among all the variables were
Table 6. Model fit

\begin{tabular}{lcccccc}
\hline$\chi^{2}$ & $d f$ & $P$-value & GFI & NFI & CFI & RMR \\
\hline 178.245 & 81 & 0.000 & 0.928 & 0.909 & 0.946 & 0.041
\end{tabular}

$d f$, degrees of freedom; GFI, goodness-of-fit-index; NFI, normed fit index; CFI, comparative fit index; RMR, root mean square residual.

Table 7. Path testing in the model and direct effects among the variables

\begin{tabular}{llcccc}
\hline Hypothesis & Hypothesis course & $\begin{array}{c}\text { Course } \\
\text { coefficient }\end{array}$ & $\begin{array}{c}\text { Standard } \\
\text { error }\end{array}$ & t-value & Result \\
\hline H1 & $\begin{array}{c}\text { Inner behavior } \rightarrow \\
\text { job burnout }\end{array}$ & -0.563 & 0.078 & $-7.218^{* * *}$ & Accept \\
H2 & $\begin{array}{c}\text { Surface behavior } \rightarrow \\
\text { job burnout }\end{array}$ & 0.332 & 0.081 & $4.099^{* * *}$ & Accept \\
H3 & $\begin{array}{c}\text { Job burnout } \rightarrow \\
\text { occupational identity }\end{array}$ & -0.415 & 0.077 & $-5.389^{* * *}$ & Accept \\
H4 & $\begin{array}{c}\text { Inner behavior } \rightarrow \\
\text { occupational identity }\end{array}$ & 0.246 & 0.092 & $2.673^{* *}$ & Accept \\
H5 & $\begin{array}{c}\text { Surface behavior } \rightarrow \\
\text { occupational identity }\end{array}$ & -0.271 & 0.121 & $-2.239^{*}$ & Accept \\
& & & & \\
\hline
\end{tabular}

${ }^{*} P<0.05 .{ }^{* *} P<0.01 .{ }^{* * *} P<0.001$.

significant, as shown in Table 5 , and there were no variables that showed a high correlation of 0.08 or higher, which is the standard value of multicollinearity. It can thus be concluded that the scales that were used in this study may have discrimination validity.

\section{Evaluation of the fitness of the research model}

The AMOS 20.0 program was used to verify the relationships among internal behavior, surface behavior, job burnout, and occupational identity via confirmatory factor analysis. The maximum likelihood method was used for estimating the parameters of the structural model, while the verification results of the fitness of the research model are as follows, as shown in Table 6: $\chi^{2}=178.245$; goodness-of-fit-index $=0.928$; normed fit index $=0.909$; comparative fit index $=0.946$; and root mean square residual $=0.041$. These suggest that the research model is fit for final adoption.

\section{Hypothesis test results}

The structural equation model was analyzed to clarify the relationships among internal behavior, surface behavior, job burnout, and occupational identity as components of Pilates instructors' emotional labor. The verification results based on the final research model are shown in Table 7.

The verification results of hypothesis 1 ("the internal behaviors of Pilates instructors' emotional labor have a negative effect on such instructors' job burnout") showed that the path coefficient between the two variables was statistically significant at -0.563 
$(t=-7.218 ; P=0.000)$, thereby prompting the acceptance of such hypothesis. In the empirical analysis of hypothesis 2 ("the surface behaviors of Pilates instructors' emotional labor have a positive effect on such instructors' job burnout"), the path coefficient between the two variables was found to be statistically significant at $0.332(t=4.099 ; P=0.000)$, thereby prompting the acceptance of the hypothesis. For hypothesis 3 ("Pilates instructors' job burnout has a negative effect on their occupational identity"), the path coefficient between the two variables was statistically significant at $-0.415(t=-5.389 ; P=0.000)$, thereby prompting the acceptance of the hypothesis. For hypothesis 4 ("the internal behaviors of Pilates instructors' emotional labor have a positive effect on such instructors' occupational identity"), the path coefficient between the two variables was statistically significant at $0.246(t=2.673 ; P=$ 0.01 ), thereby prompting the acceptance of the hypothesis. Finally, for hypothesis 5 ("the surface behaviors of Pilates instructors' emotional labor have a negative effect on such instructors' occupational identity"), the path coefficient between the two variables was $-0.271(t=-2.239 ; P=0.05)$, which is statistically significant, thereby prompting the acceptance of the hypothesis.

\section{DISCUSSION}

The purpose of this study was to help improve the occupational identity of Pilates instructors by empirically investigating the relationships among their emotional labor, job burnout, and occupational identity, which may lead to the improved quality of the services they provide to their clients. This chapter focuses on the analysis results that were obtained.

Internal behaviors of Pilates instructors' emotional labor showed a statistically significant effect on such instructors' job burnout. This result is consistent with the finding of another study that the emotional labor of daily sports and taekwondo instructors reduces their job burnout (Lee et al., 2013). Given that this result is also consistent with those regarding the relationship between emotional labor and job burnout in other occupational areas, such as call center counselors (Bok, 2012), it was confirmed that efforts to express one's emotions can have a negative effect on job burnout, which reduces the sense of job accomplishment.

First, the results of this study suggest that the number of Pilates adherents has increased along with the increase of Pilates instructors amid the current health craze. It is highly likely, however, that Pilates instructors' job burnout due to the emotional labor that occurs in their face-to-face meetings with their clients decreases their work efficiency, thereby lowering the quality of the services that they provide to their clients. It is therefore necessary to ensure that efficient training should be systematically provided to Pilates instructors to offset their emotional labor and job burnout.

Second, the surface behaviors of the Pilates instructors' emotional labor were shown to have a statistically significant effect on job burnout. This shows that job burnout stemming from emotional labor such as exaggerated expressions of a persuasive smile that occur during the face-to-face meetings with the clients can lead to job burnout, which again reduces the sense of job accomplishment, consistent with the result that the more one performs emotional labor on the surface behavior, the higher its effect will be on the subfactors of job burnout, such as emotional exhaustion, impersonalization, and deterioration of sense of accomplishment (Kim and Han, 2008).

On the other hand, studies on the emotional labor and job burnout of elderly physical education instructors showed that their effects on both emotional labor and internal behavior (indepth behavior) were not statistically significant. It is understood that the positive interaction in the relationship between the instructors who provide the service and their clients, or the instructors' commitment to elderly physical education, along with the formation of sympathy in the instruction process, reduces instruction fatigue. Based on these conflicting results, the results can be interpreted otherwise given that Pilates class is a space for seeking profit.

Therefore, the surface behavior of emotional labor is important in the effort to improve the quality of the services rendered to the general Pilates clients, but it can also accelerate job burnout and may result in a decrease in job efficiency, prompting the conclusion that it is more likely to act as a cause of job turnover. Therefore, solving these problems will require a commitment to try to internalize service provision itself, which corresponds to surface actions, with focus on the internalization of emotional labor, along with the necessary control capability to adjust the level of emotions expressed and services rendered.

Third, the job burnout of Pilates instructors was proven to have a statistically significant negative effect on their occupational identity, which is consistent with the finding of another study that correlated job burnout with occupational identity, job burnout, occupational identity, and turnover intention: that job burnout has a statistically significant effect on occupational identity (Maslach and Leiter, 2016). In the case of emotional exhaustion as a characteristic of job burnout, increased emotional contact with others will result in limitations in one's emotional interaction with others, which again inflicts emotional stress and frustration 
on human contact (Leiter and Maslach, 1986). As a result, the negative emotions that occur in the same context are consistent with the results of other empirical studies that reported negative effects on the occupational identity of employees.

The aforementioned results can be interpreted as burnout behaviors that occur in the job process, such as indifference to the people around oneself and decrease in one's sense of accomplishment due to mental burnout, which again degrades the external or internal job satisfaction. A certain amount of resting space and time will be needed to prevent job burnout, as a preliminary effort to increase the occupational identity. In addition, it will be necessary to provide Pilates instructors with opportunities to check their own job burnout status, to boost their occupational identity.

Fourth, the internal behaviors of the Pilates instructors' emotional labor showed a statistically significant positive effect on their occupational identity, suggesting that the Pilates instructors' emotional labor (e.g., the effort to maintain a good emotional state and express good impressions and sincere emotions to one's clients) increases their occupational identity when the inner workings increase. This is interpreted to be capable of creating an inner state that can provide occupational identity as it gives meaning. As one of the researches that support this interpretation, a study on the emotional labor, job burnout, and customer orientation of taekwondo instructors revealed that internal action has a positive effect on customer orientation as an operating mechanism that can induce internal satisfaction (Brotheridge and Grandey, 2002; Jhi, 2012). These results can be interpreted to mean that emphasizing emotional labor has a negative effect on occupational identity. In other words, the increasing intensity of emotional labor can be interpreted as emphasizing external actions to fit the conditions or situation, rather than as internal actions. Therefore, the instructors themselves will be required to practice the process of internalizing the mission consciousness of the educational service program provided by them, and to undergo education and training so that they could objectively accept a situation involving such a series of emotional labor, to enhance the internal emotional labor of Pilates instructors.

Fifth, the surface behaviors of the Pilates instructors' emotional labor were proven to have a statistically significant negative effect on such instructors' occupational identity. These results support the result of previous researches that emotional labor has a negative impact on occupational identity (Sy et al., 2006). These results reconfirm that the surface behaviors of emotional labor have a negative effect on occupational identity. These results are believed to be due to the fact that instructors are trained and coached on the emotional expression of a smile as well as on the ability to express and hide real emotions, which are taken in the context of the educational service provided by Pilates instructors to their clients.

In conclusion, the purpose of this study was to empirically demonstrate the relationships among the emotional labor, job burnout, and occupational identity of Pilates instructors. Based on the results of this study, the following conclusions are drawn: (a) the internal behaviors of Pilates instructors' emotional labor have a negative effect on such instructors' job burnout; (b) the surface behaviors of Pilates instructors' emotional labor have a positive effect on such instructors' job burnout; (c) the job burnout of Pilates instructors has a negative effect on their occupational identity; (d) Pilates instructors' emotional labor has a positive effect on their occupational identity; and (e) the surface behaviors of Pilates instructors' emotional labor have a negative effect on such instructors' occupational identity. Based on these results, therefore, it can be said that it is important for Pilates instructors to manage their emotions. In other words, job training for supervisors, specifically on emotional management, can prevent the deterioration of their occupational identity stemming from job burnout.

\section{CONFLICT OF INTEREST}

No potential conflict of interest relevant to this article was reported.

\section{REFERENCES}

Austin EJ, Dore TC, O'Donovan KM. Associations of personality and emotional intelligence with display rule perceptions and emotional labour. Pers Individ Dif 2008;44:679-688.

Bok MJ. The effects of emotional labor on job burnout, organizational citizenship behavior and work-family conflict among call center employees. Korean J Hum Ecol 2012;21:257-267.

Brotheridge CM, Grandey AA. Emotional labor and burnout: comparing two perspectives of "people work". J Vocat Behav 2002;60:17-39.

Brotheridge CM, Lee RT. Testing a conservation of resources model of the dynamics of emotional labor. J Occup Health Psychol 2002;7:57-67.

Bullo V, Bergamin M, Gobbo S, Sieverdes JC, Zaccaria M, Neunhaeuserer D, Ermolao A. The effects of Pilates exercise training on physical fitness and wellbeing in the elderly: a systematic review for future exercise prescription. Prev Med 2015;75:1-11.

Grandey AA. Emotion regulation in the workplace: a new way to conceptualize emotional labor. J Occup Health Psychol 2000;5:95-110. 
Hochschild AR. Emotion work, feeling rules, and social structure. Am J Sociol 1979;85:152-173.

Jhi SD. A study on the job satisfaction of senior welfare facilities employees focused on emotional labor as moderator. Public Policy Rev 2012; 26:113-139.

Kim SH. The effect of the communication satisfaction on job satisfaction and organizational commitment of personal trainer in fitness center. J Coach Dev 2011;13:45-54.

Kim YJ, Han J. Two types of emotional labor their impacts on job burnout of service workers. J Organ Manag 2008;32:95-128.

Koo BS, Chung YR, Kim DK. Appreciation for occupational socialization through life history research of a personal trainer. J Coach Dev 2010;12:3-16.

Lee JH, Li JL, Lee SK, Jang WS. Correlations among the emotional labor, job burnout and customer orientation of taekwondo instructors. Korean J Sport Sci 2013;24:757-767.

Lee YH. Chelladurai P, Kim Y, Mallett C. Emotional labor in sports coaching: development of a model. Int J Sports Sci Coach 2016;10:561-576.

Leiter MP, Maslach C. The impact of interpersonal environment on burnout and organizational commitment. J Organ Behav 1986;9:297-308.

Maguire JS. Fit and flexible: the fitness industry, personal trainers and emotional service labor. Sociol Sport J 2001;18:372-402.

Maslach C, Jackson SE. The measurement of experienced burnout. J Occup Behav 1981;2:99-113.

Maslach C, Leiter MP. Understanding the burnout experience: recent research and its implications for psychiatry. World Psychiatry 2016;15: 103-111.

Melgosa J. Development and validation of the occupational identity scale. J Adolesc 1987;10:385-397.

Roh SY. An exploration of implications for the development of Pilates instructor system through identification of instructors' difficulties. J Exerc Rehabil 2016;12:355-362.

Roh SY. The influence of physical self-perception of female college students participating in Pilates classes on perceived health state and psychological wellbeing. J Exerc Rehabil 2018;14:192-198.

Sy T, Tram S, O'Hara LA. Relation of employee and manager emotional intelligence to job satisfaction and performance. J Vocat Behav 2006; 68:461-473.

Yi ES, Sim KS. The relationships of emotional labor, job attachment and job satisfaction of senior sports leaders. J Sport Leisure Stud 2010;40: 443-452. 